\title{
TV parenting practices: is the same scale appropriate for parents of children of different ages?
}

Tzu-An Chen ${ }^{*}$, Teresia M O'Connor, Sheryl O Hughes, Leslie Frankel, Janice Baranowski, Jason A Mendoza, Debbe Thompson and Tom Baranowski

\begin{abstract}
Purposes: Use multidimensional polytomous item response modeling (MPIRM) to evaluate the psychometric properties of a television (TV) parenting practices (PP) instrument. Perform differential item functioning (DIF) analysis to test whether item parameter estimates differed across education, language, or age groups.

Methods: Secondary analyses of data from three studies that included 358 children between the ages of 3 and 12 years old in Houston, Texas. TV PP included 15 items with three subscales: social co-viewing, instructive parental mediation, and restrictive parenting. The multidimensional partial credit model was used to assess the performance. DIF was used to investigate the differences in psychometric properties across subgroups.

Results: Classical test theory analyses revealed acceptable internal consistency reliability (Cronbach's a: 0.72 to 0.83 ). More items displaying significant DIF were found across children's age groups than parental education or language groups. A Wright map revealed that items covered only a restricted range of the distribution, at the easier to respond end of the trait.

Conclusions: TV PP scales functioned differently on the basis of parental education, parental language, and child age, with the highest DIF among the latter. Additional research is needed to modify the scales to minimize these moderating influences. Some items may be age specific.
\end{abstract}

Keywords: TV, Parenting practices, Multidimensional, Item response modeling, Differential item functioning

\section{Introduction}

Television (TV) viewing increased among youth in the United States [1], and is considered a cause of childhood obesity [2-5]. Parenting practices to reduce children's TV viewing may be important for preventing child obesity. Parenting practices (PP) are behaviors parents use to influence their child's behaviors [6-8]. Limited psychometric analyses have been reported on TV PP scales with all having employed only classical test theory (CTT) [9]. CTT, however, is sample-dependent. In contrast, item response modeling (IRM) provides model-based measurements: trait level estimates obtained as a function of participants' responses and properties of the administered items [10,11]. For example, the participants' estimated trait level of TV

\footnotetext{
* Correspondence: anntzuac@bcm.edu

USDA/ARS Children's Nutrition Research Center, Baylor College of Medicine, 1100 Bates Street, Rm. 4012, Houston, TX, USA
}

PP depends both on a person's response to these items and the items' parameters.

Valid measures are needed both to understand how PP influence child behaviors and to measure mediating variables in parenting change interventions. PP that influence child TV viewing may differ depending on parental education level, child's age or parent's understanding of items that may differ by language [12-14]. Such differences could pose serious problems for validity by making it difficult to compare parameter estimates across these variables or across studies. Multidimensional polytomous item response modeling (MPIRM) enables differential item functioning (DIF) analysis [15] for multidimensional scales.

The aim of this study was to use MPIRM and DIF to examine the item and person characteristics of TV PP scales across education, language, and age groups.
C Biomed Central

(c) 2013 Chen et al.; licensee BioMed Central Ltd. This is an Open Access article distributed under the terms of the Creative Commons Attribution License (http://creativecommons.org/licenses/by/2.0), which permits unrestricted use, distribution, and reproduction in any medium, provided the original work is properly cited. 


\section{Methods}

\section{Participants}

Children $(\mathrm{n}=358)$ between 3 to 12 years old (yo) in Houston, Texas, were included in the present analyses and the data were assembled from three studies: a physical activity intervention using Wii Active Video Games (Wii, $\mathrm{n}=78$ ) [16], a first line obesity treatment intervention Helping HAND (Healthy Activity and Nutrition Directions) ( $\mathrm{HH}, \mathrm{n}=40)$ [17], and one cross-sectional study, Niños Activos (NA, $\mathrm{n}=240$ ). The Wii study recruited 84 children from multiple sources to participate in a 13-week exergame intervention in 2010. The inclusionary criteria targeted children 9-12 yo, whose BMI were within the 50-99th percentile range. Details have been reported elsewhere [16]. HH recruited 40 5-8 yo children whose BMI were within 85-99th percentile range to participate in an obesity treatment study in pediatric primary care. Details have been reported elsewhere [17]. Niños Activos recruited 240 3-5 yo Hispanic children from Houston, TX with no restrictions on BMI to participate in a study assessing influences on child PA. TV PP was assessed at baseline in all studies.

The Institutional Review Board of Baylor College of Medicine approved all three study protocols. Signed informed consent and assent were obtained from each parent and child.

\section{Instrument}

All parents self-completed in English or Spanish a TV PP questionnaire [9] which was originally developed to assess the TV mediation styles of 519 Dutch parents of children 5-12 years old. In the original study, this scale contained 15 items distributed across 3 subscales: restrictive mediation (5 items, $\alpha=0.79$ ), instructive mediation ( 5 items, $\alpha$ $=0.79$ ) and social co-viewing (5 items, $\alpha=0.80$ ) [9]. Restrictive mediation was defined as the parent determining the duration of TV viewing and specifying appropriate programs; instructive mediation was the parent explaining the meaning of TV programs and the acceptability of characters' behaviors; and social co-viewing was a parent watching TV together with his/her child [17-19].

Items in the Wii and $\mathrm{HH}$ studies featured the same four response options as in the original studies (Never, Rarely, Sometimes, and Often). Items in the NA study featured five response options (Never, Rarely, Sometimes, Often and Always). To facilitate analyses, category response curves (CRCs) were depicted on the NA sample to determine the collapse of response categories. Parents provided demographic information in all three studies at baseline.

\section{Analyses \\ Classical test theory}

Item difficulty (mean) and item discrimination (corrected item-total correlations, CITC) were first assessed for the
TV PP scales, and Cronbach's alpha assessed internal consistency reliability. Criteria for acceptable CITC and internal consistency reliability were defined as greater than 0.30 and 0.70 , respectively [20]. All CTT analyses were conducted using Statistical Analysis Systems [21].

\section{Item response modeling (IRM)}

The primary assumption of IRM, unidimensionality, was tested using exploratory factor analysis in SPSS [22] for each subscale. Unidimensionality was satisfied if the scree plots showed one dominant factor, the solution explained at least $20 \%$ of variance for the first factor, and the factor loadings were $>0.30$ [23]. An IRM model which best explained the data structure was selected after unidimensionality was confirmed in each subscale.

Polytomous IRM models were used because the TV PP items presented multiple response possibilities [24,25]. Polytomous IRM modeled the probability of endorsing one response category over another, referred to as a threshold parameter, indicating the probability of responding at or above a given category. For an item with four response options (e.g., never, rarely, sometimes, and often), three thresholds exist (1) from "never" to "rarely", (2) from "rarely" to "sometimes", and (3) from "sometimes" to "often". The item threshold locations were determined along the latent trait continuum. The latent trait estimates from IRM can be related to the raw scores of the TVPP scale using non-linear transformation.

Category response curves (CRC) show the probability of a response in a particular category for a given trait level. The number of CRCs equals the number of response options. In this study, every item has four CRCs, and each CRC shows the probability of endorsing the particular response at different levels of the latent trait. For example, CRCs for response option "rarely" show at what latent trait level participants will be more likely to endorse "rarely" than the other three response categories. The sum of the response probabilities equals 1.0 at any location along the underlying trait continuum. CRCs can also be used to identify the most likely response at various levels of a latent trait.

Item-person maps, often called Wright maps (with units referred to as $\log$ odds), depicted the distributions of scale items with that of the respondents along the latent trait on the same scale. The dashed vertical line presents the latent trait in logits which were specified on the far left of the map. A logit of 0 in this map implies a moderate amount of latent trait. The location of thresholds in a Wright map shows the point at which the probability of the scores below $k$ equals the probability of the scores $k$ and above. For example, the location of Threshold 1 shows the amount of latent trait of the corresponding sub-scale, e.g. restrictive TVPP, a person must possess if there is a 0.5 probability of selecting "rarely" over "never". 
Large gaps along the difficulties continuum imply that additional items will help distinguish within that particular range of difficulty. Since the TV PP instrument contained three sub-scales, two multidimensional polytomous models were considered: partial credit (PCM) [26], and rating scale models (RSM) $[27,28]$. RSM is a special case of the PCM where the response scale is fixed for all items, i.e., the response threshold parameters are assumed to be identical across items. The relative fit of RSM and PCM was evaluated by considering the deviance difference, where $d f$ was equal to the difference in the number of estimated parameters between the two models.

Item fit was assessed using information-weighted fit statistic (infit) and outlier-sensitive fit statistic (outfit) mean square index (MNSQ) which have possible ranges from zero to infinity. Infit MNSQ is based on informationweighted sum of squared standardized residuals; outfit MNSQ is a sum of squared standardized residuals [29]. An infit or outfit MNSQ value of one indicates the observed variance equals the expected variance. MNSQ values greater than, or smaller than, one indicate the observed variance is greater, or smaller, than the expected, respectively. Infit or outfit MNSQ values greater than 1.3 indicate poor item fit (for $\mathrm{n}<500[30,31]$ with significant $t$-values. Concerning thresholds, outfit MNSQ values greater than 2.0 indicate misfit, identifying candidates for collapsing with a neighboring category $[29,32]$.

\section{Differential item functioning (DIF)}

Participants with the same underlying trait level, but from different groups, may have different probabilities of endorsing an item. DIF was assessed by an item-by -group interaction term [33,34], with a significant chisquare for the interaction term indicating DIF. Items display DIF if the ratio of the item-by-group parameter estimates to the corresponding standard error exceeds 1.96. A finding of DIF by gender means that a male and a female with the same latent trait level responded differently to an item, suggesting that respondents' interpretation of the item differed for males and females.

The magnitude of DIF was determined by examining the differences of the item-by-group interaction parameter estimates. Because the parameters were constrained to be zero, if only two groups were considered the magnitude of DIF difference was twice the estimate of the first focal group. If comparison was made among three or more groups, the magnitude of DIF was the difference of the interaction term estimate of the corresponding groups. Items were placed into one of three significant DIF categories depending on the effect size: small (difference $<0.426)$, intermediate $(0.426<$ difference $<0.638$ ), and large (difference $>0.638$ ) DIF $[35,36]$. ACER (Australian Council for Educational Research) ConQuest [37] was used for all IRM analyses.

\section{Results}

\section{Descriptive statistics}

Participant demographic characteristics are shown in Table 1 by source. Parental education level was almost evenly distributed across the three studies with $50.7 \%$ of all participants reporting a high school education or less education. Because these three original studies recruited kids at different age ranges, percentages by age group in the combined sample were proportional to the original study's sample size; $57.8 \%$ completed the English version. The majority of participants were Hispanic (79.1\%).

\section{Category response curves (CRCs)}

The CRCs for the response category "often" mostly never peaked for the NA sample across the 15 items, indicating that "often" never had the highest probability of being selected for most items. Therefore, the response categories "Often" and "Always" were collapsed in the NA sample. Figure 1 shows CRCs for item 2 across the three original samples (Wii, $\mathrm{HH}$ and NA). The curve for "rarely" never peaked in two of the samples, indicating that respondents were unlikely to choose "rarely". CRCs revealed that respondents did not use all response categories (usually only 3 ), and response category use differed by sample. (CRCs for the remaining items are available upon request).

\section{Classical test theory}

The percentage of variance explained by the one-factor solution was $60 \%, 60 \%$ and $48 \%$ for social co-viewing, instructive mediation and restrictive subscales, respectively.

Table 1 Demographic characteristics of respondents

$\frac{\text { Wii }}{n} \frac{\text { HH }}{n} \frac{\text { NA }}{n} \frac{\text { Total }}{n} \frac{\%}{n}$

\section{Education}

$\begin{array}{lllllllll}\text { High School or Less } & 15 & 19.23 & 27 & 67.50 & 139 & 58.16 & 181 & 50.70\end{array}$

$\begin{array}{lllllllll}\text { Above High School } & 63 & 80.77 & 13 & 32.50 & 100 & 41.84 & 176 & 49.30\end{array}$

\section{Language}

English

Spanish

Ethnicity

$\begin{array}{lllllllll}\text { Hispanic } & 10 & 12.8 & 33 & 82.50 & 240 & 100.00 & 283 & 79.05\end{array}$

$\begin{array}{lllllllll}\text { Non-Hispanic } & 68 & 87.2 & 7 & 17.50 & 0 & 0.00 & 75 & 20.95\end{array}$

Age

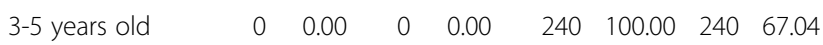



9-12 years old $\quad \begin{array}{llllllll}78 & 100.00 & 0 & 0.00 & 0 & 0.00 & 78 & 21.79\end{array}$

Note. Wii $=$ children participating in the Wii exergame study [16]; $\mathrm{HH}=$ children participating in the Helping Hand study [17]; NA = children participating in the Niños Activos study. 

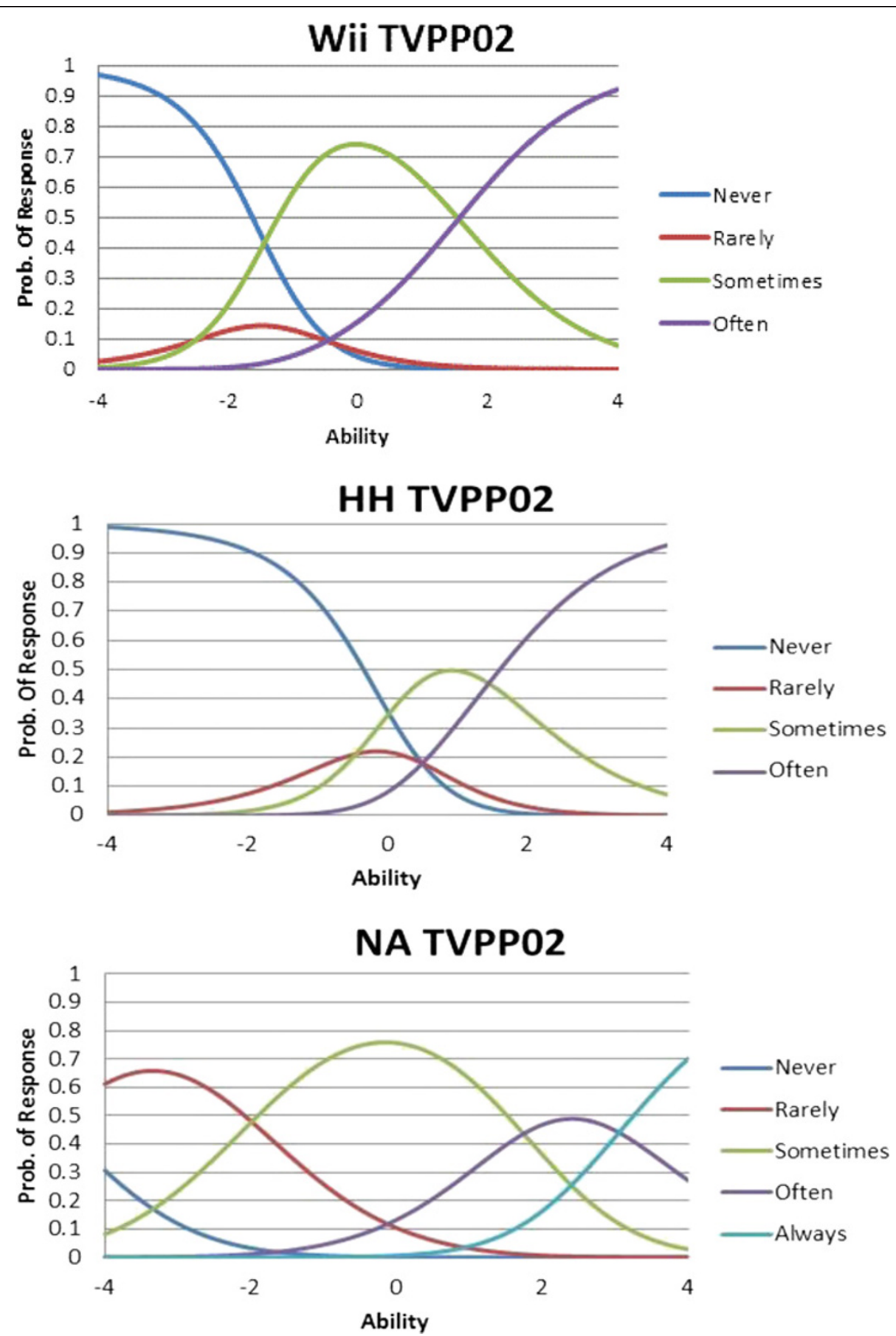

Figure 1 Category Response Curves for Item 2: “How often do you explain what something on TV really means?"

The scree plots revealed one dominant factor and factor loadings were $>0.30$ for all three subscales.

Item difficulty (item means) ranged from $3.16(\mathrm{SD}=$ $0.49)$ to $3.67(\mathrm{SD}=0.62)$, indicating that on average respondents reported frequently performing the PP. Internal consistencies were good for social co-viewing $(\alpha=$ $0.83)$; and instructive parental mediation, $(\alpha=0.83)$; and adequate for restrictive mediation $(\alpha=0.72)$. CITCs acceptably ranged from 0.41 to 0.70 .

\section{IRM model fit}

The chi-square $\left(\chi^{2}\right)$ deviance statistic was calculated by considering differences in model deviances (RSM: 8749.63; PCM: 8485.99) and differences in numbers of 
parameters (RSM: 23; PCM: 51) for the nested models. The chi-square test of the deviance difference showed RSM significantly reduced model fit $(\Delta$ deviance $=$ 263.64, $\Delta d f=28, \mathrm{p}<0.0001)$; thus, further analyses employed multidimensional PCM.

\section{Item fit}

Item difficulties are summarized in Table 2. Assuming a multidimensional PCM, only one item (item 2) exceeded the criterion guideline (> 1.3). Item 14 was flagged as the only misfit item when taking into account the difference in parental education level (infit/outfit MNSQ = 1.37), in language (infit/outfit $M N S Q=1.32$ ), or in child's age (infit $M N S Q=1.36$; outfit $M N S Q=1.42$ ). Misfit values were relatively small; therefore, the items were retained in the ensuing analyses.

\section{Item-person fit Wright map}

Figure 2 presents the multidimensional PCM item-person maps. Person, item and threshold estimates were placed on the same map where " $x$ " on the left side represented the trait estimates of a person with the parent scoring in the highest TV PP range placed at the top of the figure. Item and threshold difficulties were presented on the right side, with the more difficult response items and thresholds at the top. The range of item difficulties was narrow (logits ranged from -1.02 to 0.72); the distribution of item difficulties did not match that of individuals for each dimension. In each subscale category, most parents found it easy to endorse these items. Many items' (1, 2, 4-6, 10 and 1215) first step threshold did not coincide with participants at the lower end of TV PP.

\section{Differential item functioning (DIF)}

Item difficulty differences between demographic groups are presented in Table 3. One, five and nine items exhibited significant DIF between educational level, language, and child's age groups, respectively (Table 3). Only item 2 had significant DIF by educational level at 0.67 , a large DIF effect: it was easier for parents with higher education level to endorse item 2. Moderate DIF was detected for item 2 and small DIF for items 5, 7, 8, and 9 by use of the English or Spanish version. The Spanish version users found it somewhat easier to endorse items 5,8 , and 9 , but more difficult to endorse items 2 and 7. Medium DIF was detected for items 8 and 11 between children of ages 3-5 years and children of ages 5-8. Large DIF was indicated for item 2 between children 3-5 yo and children 9-12 yo, and

Table 2 Item description, item difficulty, and misfit item(s)

\begin{tabular}{|c|c|c|c|c|c|c|c|}
\hline \multirow[b]{2}{*}{ Items } & \multirow[b]{2}{*}{ Item questions } & \multirow[b]{2}{*}{ All } & \multirow[b]{2}{*}{$\begin{array}{l}\text { Low } \\
\text { edu. }\end{array}$} & \multirow[b]{2}{*}{ English } & \multicolumn{3}{|l|}{ Age } \\
\hline & & & & & $\begin{array}{l}3-5 \\
\text { yo }\end{array}$ & $\begin{array}{l}5-8 \\
\text { yo }\end{array}$ & $\begin{array}{l}9-12 \\
\text { yo }\end{array}$ \\
\hline & Social Co-viewing (Cronbach's alpha $=0.83)$ & & & & & & \\
\hline 6 & How often do you laugh with your child about the things you see on TV? & -1.02 & -0.16 & 0.00 & 0.06 & -0.29 & 0.23 \\
\hline 1 & How often do you watch TV together because you both like a program? & 0.04 & 0.06 & -0.10 & -0.11 & 0.17 & -0.06 \\
\hline 12 & How often do you watch TV together because of a common interest in a program? & 0.14 & $0.02^{\mathrm{b}}$ & $0.15^{c}$ & $0.23^{d}$ & $-0.11^{d}$ & $-0.12^{\mathrm{d}}$ \\
\hline 14 & How often do you watch TV together just for fun? & 0.20 & 0.24 & -0.21 & 0.08 & 0.08 & -0.16 \\
\hline \multirow[t]{2}{*}{5} & How often do you watch your favorite program together? & 0.64 & -0.15 & 0.15 & -0.26 & 0.15 & 0.11 \\
\hline & Instructive Mediation (Cronbach's alpha =0.83) & & & & & & \\
\hline 2 & How often do you explain what something on TV really means? & $-0.59^{\mathrm{a}}$ & 0.33 & -0.30 & 0.21 & 0.47 & -0.68 \\
\hline 4 & How often do you try to help your child understand what she/he sees on TV? & -0.40 & -0.04 & -0.05 & -0.21 & 0.01 & 0.19 \\
\hline 8 & How often do you point out why some things actors do are bad? & 0.08 & -0.14 & 0.17 & 0.14 & -0.36 & 0.22 \\
\hline 10 & How often do you point out why some things actors do are good? & 0.18 & -0.02 & 0.03 & 0.06 & -0.06 & 0.00 \\
\hline \multirow[t]{2}{*}{13} & How often do you explain the motives of TV characters? & 0.72 & -0.13 & 0.16 & -0.20 & -0.07 & 0.27 \\
\hline & Restrictive (Cronbach's alpha =0.72) & & & & & & \\
\hline 15 & How often do you forbid your child to watch certain programs? & -0.38 & 0.04 & -0.06 & 0.01 & -0.18 & 0.17 \\
\hline 9 & $\begin{array}{l}\text { How often do you tell your child to turn off the TV when he/she is watching an } \\
\text { unsuitable program? }\end{array}$ & -0.25 & -0.06 & 0.13 & 0.10 & 0.01 & -0.10 \\
\hline 3 & How often do you specify in advance the programs that may be watched? & -0.07 & 0.02 & 0.03 & 0.16 & -0.26 & 0.10 \\
\hline 11 & How often do you restrict the amount of TV your child can watch? & 0.09 & -0.07 & 0.07 & -0.25 & 0.20 & 0.05 \\
\hline 7 & How often do you set specific viewing hours for your child? & 0.62 & 0.07 & -0.17 & -0.01 & 0.23 & -0.22 \\
\hline
\end{tabular}

Note. ${ }^{\mathrm{a}}$ Misfit item (Item 2) Outfit MNSQ $=1.34 ;{ }^{\mathrm{b}}$ Misfit item (Item 14) Infit/Outfit MNSQ $=1.37$; ${ }^{\mathrm{c}}$ Misfit item (Item 14) Infit/Outfit MNSQ = 1.32; ${ }^{\mathrm{d}}$ Misfit item (Item 14) Infit MNSQ = 1.36; Outfit MNSQ = 1.42 .

Item difficulties for High edu. and Spanish were not shown here since the estimates were constrained to be zero, the item difficulty will have opposite sign if only two groups were considered. For example, item difficulty of item 1 for High edu. is -0.06 . 


\begin{tabular}{|c|c|c|c|c|c|c|c|c|c|c|c|c|}
\hline \multirow[t]{3}{*}{ Logit } & \multicolumn{3}{|c|}{ Latent Ability Distribution } & \multicolumn{3}{|c|}{ Item Distribution } & \multicolumn{6}{|c|}{ Item Threshold Distribution } \\
\hline & $\begin{array}{c}\text { Social- } \\
\text { Coviewing }\end{array}$ & $\begin{array}{l}\text { Instructive } \\
\text { Mediation }\end{array}$ & Restrictive & $\begin{array}{c}\text { Social- } \\
\text { Coviewing }\end{array}$ & $\begin{array}{l}\text { Instructive } \\
\text { Mediation }\end{array}$ & Restrictive & & $\begin{array}{c}\text { Social- } \\
\text { Coviewing }\end{array}$ & $\begin{array}{l}\text { Instructiv } \\
\text { Mediation }\end{array}$ & & Restrictive & \\
\hline & 1 & 1 & & t & 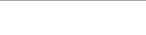 & | & I & & I & I & & 1 \\
\hline \multirow[t]{4}{*}{11} & I & 1 & & & & | & | & & I & I & & I \\
\hline & 1 & 1 & & & & | & | & & I & I & & I \\
\hline & I & 1 & & & & I & I & & I & I & & I \\
\hline & 1 & 1 & & & & | & | & & I & I & & I \\
\hline \multirow[t]{3}{*}{10} & 1 & 1 & & & & | & | & & I & I & & I \\
\hline & । & । & & & & | & | & & I & I & & I \\
\hline & 1 & 1 & & & & | & | & & I & I & & I \\
\hline \multirow[t]{4}{*}{9} & । & । & & & & | & | & & I & I & & I \\
\hline & I & 1 & & & & | & | & & I & I & & 1 \\
\hline & 1 & 1 & & & & | & | & & I & I & & I \\
\hline & I & 1 & & & & | & | & & I & I & & I \\
\hline \multirow[t]{3}{*}{8} & I & 1 & & & & | & | & & I & I & & I \\
\hline & 1 & 1 & & & & | & | & & I & I & & I \\
\hline & XI & XI & & & & | & | & & I & I & & I \\
\hline \multirow[t]{4}{*}{7} & XI & XI & & & & | & | & & I & I & & I \\
\hline & $\mathrm{x} \mid$ & 1 & & & & | & | & & I & I & & I \\
\hline & XI & XI & & & & | & | & & I & I & & I \\
\hline & $\mathrm{xXI}$ & XI & & & & | & | & & I & I & & I \\
\hline \multirow[t]{3}{*}{6} & $\mathrm{xxx} \mid$ & x। & & & & | & | & & I & I & & I \\
\hline & $\mathrm{xxx} 1$ & $\mathrm{x} \times 1$ & & & & | & | & & I & I & & I \\
\hline & $\mathrm{x} \times 1$ & $\mathrm{x} \times 1$ & & & & | & | & & I & I & & I \\
\hline \multirow[t]{4}{*}{5} & XXXI & $\mathrm{x} \times 1$ & & & & | & | & & I & I & & I \\
\hline & $\mathrm{xx} \mid$ & XXX1 & & & & | & | & & I & I & & I \\
\hline & XXXI & $\mathrm{x} \times \mathrm{x} 1$ & $\mathrm{x}$ & & & | & | & & 1 & I & & 1 \\
\hline & XXXXXI & xxxI & $\mathrm{x}$ & & & | & | & & I & I & & I \\
\hline \multirow[t]{3}{*}{4} & $\mathrm{XXX1}$ & $\mathrm{XXX} 1$ & $\mathrm{x}$ & & & | & | & & I & । & & I \\
\hline & $\mathrm{x} \times \mathrm{x} \times 1$ & $\mathrm{x} \times \mathrm{x} \times 1$ & $\mathrm{xxx}$ & & & | & | & & I & I & & I \\
\hline & $\mathrm{xxx|}$ & XXXXI & $\mathrm{xxx}$ & & & | & & 14.3 & | 2.3 & I & & I \\
\hline 3 & $x \times x \times 1$ & $x \times x \times 1$ & $\mathrm{xxx}$ & & & | & I & & I & I & & I \\
\hline & $\mathrm{xxxx|}$ & $x \times x \times x \mid$ & $\mathrm{xxxx}$ & & & | & 1 & 1.312 .3 & | 13.3 & I & & I \\
\hline & XXXI & XXXXXI & $\mathrm{XXXXXX}$ & & & | & 5 & 5.36 .3 & | 4.3 & I & & I \\
\hline & XXXXI & $\mathrm{xxxx|}$ & $\mathrm{xxxxxx}$ & & & | & | & & I & I & & I \\
\hline 2 & $\mathrm{x} \times \mathrm{x} \times 1$ & $\mathrm{XXXXXXY}$ & $\mathrm{x} \times \mathrm{XXXXX \times X}$ & & & | & | & & 10.3 & I & & I \\
\hline & XXXXI & $\mathrm{XXXX|X}$ & XXXXXXXXX & & & | & | & & 18.3 & I & & I \\
\hline & $\mathrm{xxx} 1$ & $\mathrm{xxxx|}$ & $\mathrm{xxxxxxx}$ & & & | & | & & I & & 3.311 .315 .3 & \\
\hline 1 & $\mathrm{x} \times \mathrm{x} 1$ & $\mathrm{x} \times \mathrm{x} \times 1$ & $\mathrm{XXXXXX}$ & & & | & | & & I & I & & I \\
\hline & $\mathrm{x} \times \mathrm{x} \mid$ & $\mathrm{x} \times \mathrm{x} 1$ & $\mathrm{xxxxxx}$ & & 13 & 17 & | & & I & & 7.3 & I \\
\hline & $\mathrm{xXI}$ & $\mathrm{xxx} 1$ & $\mathrm{xxxxx}$ & & & | & I & & I & & 9.215 .2 & I \\
\hline 0 & xI & $\mathrm{x} \times 1$ & $\mathrm{x} x \mathrm{x}$ & 11214 & 810 & | 11 & | & & I & I & 7.29 .3 & I \\
\hline & $\mathrm{xI}$ & XI & $x x$ & & & 139 & I & & | 13.2 & & 9.1 & I \\
\hline & $\mathrm{xXI}$ & XI & $\mathrm{x}$ & & 4 & 15 & | & & | 2.24 .210 .2 & & 3.211 .2 & 1 \\
\hline & 1 & XI & $\mathrm{x}$ & & 2 & | & | 1 & 1.212 .214 .2 & 8.18 .2 & & 3.17 .111 .1 & I \\
\hline-1 & XI & I & & 6 & & I & | 5 & 5.26 .2 & I & I & & I \\
\hline & 1 & 1 & & & & I & 15 & 5.16 .1 & | 10.1 & & 15.1 & I \\
\hline & 1 & 1 & & & & I & | 1 & 12.1 & 4.1 & I & & I \\
\hline-2 & 1 & 1 & & & & I & | & & I & I & & I \\
\hline & I & I & & & & I & 1 & 1.1 & I & I & & I \\
\hline & 1 & 1 & & & & । & 1 & 14.1 & | 2.113 .1 & I & & I \\
\hline & 1 & 1 & & & & I & | & & I & I & & 1 \\
\hline-3 & 1 & 1 & & & & I & I & & I & I & & I \\
\hline & 1 & 1 & & & & I & I & & I & I & & I \\
\hline & 1 & 1 & & & & I & | & & I & I & & I \\
\hline-4 & 1 & 1 & & & & I & | & & I & I & & I \\
\hline & 1 & 1 & & & & I & | & & I & I & & I \\
\hline & 1 & 1 & & & & I & I & & 1 & I & & 1 \\
\hline & 1 & 1 & & & & I & | & & I & I & & I \\
\hline-5 & I & 1 & & & & I & I & & I & I & & I \\
\hline & 1 & 1 & & 1 & _t & I & | & & 1 & I & & 1 \\
\hline
\end{tabular}

Each ' $X$ ' represents 4.5 cases; labels for thresholds show the levels of item and step, respectively.

Figure 2 Wright Map of TV PP Scale ( $n=358$ ). 
Table 3 Item description and estimates of DIF where significant

\begin{tabular}{|c|c|c|c|c|c|c|c|c|}
\hline \multirow{3}{*}{ Items } & \multirow{3}{*}{ Item questions } & \multicolumn{2}{|l|}{ CTT } & \multirow{2}{*}{\multicolumn{5}{|c|}{$\begin{array}{c}\text { IRM } \\
\text { Difficulty differences }\end{array}$}} \\
\hline & & \multirow{2}{*}{$\begin{array}{l}\text { Mean } \\
\text { (SD) }\end{array}$} & \multirow[t]{2}{*}{$\overline{\text { CITC }}$} & & & & & \\
\hline & & & & $\begin{array}{l}\text { Low edu.- } \\
\text { High edu. }\end{array}$ & $\begin{array}{l}\text { English- } \\
\text { Spanish }^{\mathbf{b}}\end{array}$ & $\begin{array}{l}3-5 \text { yo }-5-8 \\
\text { yo }\end{array}$ & $\begin{array}{l}3-5 \text { yo-9-12 } \\
y^{\text {d }}\end{array}$ & $\begin{array}{l}5-8 \text { yo -9-12 } \\
\text { yo }\end{array}$ \\
\hline & Social Co-viewing (Cronbach's alpha $=0.83)$ & & & & & & & \\
\hline 1 & How often do you watch TV together because you both like a program? & $3.42(0.67)$ & 0.68 & & & & & \\
\hline 5 & How often do you watch your favorite program together? & $3.35(0.74)$ & 0.7 & & $0.3^{*}$ & $-0.41^{*}$ & $-0.37^{*}$ & \\
\hline 6 & How often do you laugh with your child about the things you see on TV? & $3.67(0.54)$ & 0.62 & & & $0.35^{*}$ & & \\
\hline 12 & How often do you watch TV together because of a common interest in a program? & $3.41(0.67)$ & 0.67 & & & $0.34^{*}$ & & \\
\hline \multirow[t]{2}{*}{14} & How often do you watch TV together just for fun? & $3.35(0.67)$ & 0.51 & & & & & \\
\hline & Instructive Mediation $($ Cronbach's alpha $=0.83)$ & & & & & & & \\
\hline 2 & How often do you explain what something on TV really means? & $3.47(0.63)$ & 0.54 & $0.67^{* * *}$ & $-0.6^{* *}$ & & $0.88^{* * *}$ & $1.15^{* * *}$ \\
\hline 4 & How often do you try to help your child understand what she/he sees on TV? & $3.53(0.66)$ & 0.58 & & & & $-0.4^{*}$ & \\
\hline 8 & How often do you point out why some things actors do are bad? & $3.53(0.74)$ & 0.65 & & $0.34^{*}$ & $0.5^{* *}$ & & \\
\hline 10 & How often do you point out why some things actors do are good? & $3.44(0.74)$ & 0.69 & & & & & \\
\hline \multirow[t]{2}{*}{13} & How often do you explain the motives of TV characters? & $3.19(0.77)$ & 0.7 & & & & & \\
\hline & Restrictive (Cronbach's alpha $=0.72)$ & & & & & & & \\
\hline 3 & How often do you specify in advance the programs that may be watched? & $3.47(0.76)$ & 0.41 & & & $0.41^{*}$ & & $-0.36^{*}$ \\
\hline 7 & How often do you set specific viewing hours for your child? & $3.16(0.96)$ & 0.49 & & $-0.33^{*}$ & $-0.24^{*}$ & & \\
\hline 9 & How often do you tell your child to turn off the TV when he/she is watching an unsuitable program? & $3.65(0.74)$ & 0.42 & & $0.25^{*}$ & & & \\
\hline 11 & How often do you restrict the amount of TV your child can watch? & $3.39(0.78)$ & 0.56 & & & $-0.46^{* *}$ & $-0.3^{*}$ & \\
\hline 15 & How often do you forbid your child to watch certain programs? & $3.51(0.72)$ & 0.54 & & & & & \\
\hline
\end{tabular}

Note. ${ }^{*}$ small effect (difference $\left.<0.426\right)$; ** moderate effect $(0.426<$ difference $<0.638)$; ${ }^{* * *}$ large effect (difference $\left.>0.638\right)$.

${ }^{a}$ Positive numbers, easier for high education; Negative value, easier for low education; ${ }^{b}$ Positive numbers, easier for Spanish; Negative value, easier for English.

'Positive numbers, easier for 5-8 years old; Negative value, easier for 3-5 years old; ${ }^{\mathrm{d} P o s i t i v e ~ n u m b e r s, ~ e a s i e r ~ f o r ~ 9-12 ~ y e a r s ~ o l d ; ~ ' N e g a t i v e ~ v a l u e, ~ e a s i e r ~ f o r ~ 3-5 ~ y e a r s ~ o l d . ~}$ 
between children 5-8 yo and children $9-12$ yo. It was easier for parents with older children to endorse items 6,12 , 2 , and 8 and for parents with younger children to endorse items $5,4,7$, and 11 .

\section{Discussion}

This is the first study to present an analysis using multidimensional PCM for a TV PP instrument. While CTT analyses indicated that the scales yielded generally acceptable (good or adequate) reliability, item characteristic curves revealed respondents used only 3 of 4 response categories. Thus, it appears appropriate to simplify response categories to 3 options in the future. The asymmetric distribution of items and item thresholds against individuals on the Wright map indicated the items and thresholds did not cover the more difficult to endorse end of each of the three latent variable dimensions. This suggests that items should be developed to cover the more difficult extreme end for each dimension.

DIF analyses indicated that some items did not behave the same way across subgroups. A large amount of DIF was identified for item 2 (i.e. "How often do you explain what something on TV really means?") on the basis of education of parent and age of child; medium DIF was detected for item 2 on the language version, and for items 8 and 11 on children's age. Parents with $3-5$ yo kids tended to watch favorite programs together, and more likely restricted the amount of TV viewing than parents with older kids. Parents with older kids (9-12 yo) and with higher education level showed a higher degree of agreement with explaining to their child what something on TV really meant. Parents with 5-8 yo kids were more likely to specify in advance the programs that kids may watch than the other two age groups. Parents who used the English version tended to help their kids understand the meaning of something on TV and set specific TV viewing time; while parents who completed the Spanish version tended to agree that they watched the favorite program together, pointed out why some things actors do are bad, and asked their child to turn off the TV when he/she was viewing an unsuitable program.

DIF by age group presents distinct issues. While the usual prescription for eliminating DIF is to rewrite items to enhance the clarity of meaning [38,39], it may be that these items are reasonably clear and just not equally applicable across all ages of children. This suggests that responses for such scales can only be analyzed within rather narrow age groupings. The optimal age groupings await determination in future studies with larger samples. These subscale items all reflect frequency of performance, which is common among behavioral indicators. There may be benefit in introducing a value or normative aspect to these items: should parents do each of these practices?
Several limitations exist. The response scales for the NA items (a 5-point rating scale) were different than those for items in the Wii and $\mathrm{HH}$ studies (4-point scale). Collapsing one of the response categories based on infrequent use was a reasonable accommodation, but having the same categories would have been preferred. The samples in the three studies reflected different inclusionary/exclusionary criteria and different recruitment procedures, with unknown effects on the findings. The Wii study with 9-12 yo did not include any participants using the Spanish version, therefore, DIF by age may confound language. Finally, the sample size was relatively small. While no clear standards for minimum sample size are available, Embretson and Reise [40] recommended using a sample of 500, and Reeve and Fayers [41] recommended at least 350. Finally, an interaction term was used to detect DIF. Further investigation should pursue other DIF-detection procedures (e.g., Mantel [42]; Shealy \& Stout [43,44]).

\section{Conclusion}

TVPP subscales demonstrated factorial validity and acceptable internal consistency reliability. The true latent variables demonstrated adequate fit to the data, but did not adequately cover the more difficult to respond end of each dimension; effectively used only these response categories; and showed differential item functioning, especially by age. While the scales can be cautiously used, further formative work is necessary.

\section{Abbreviations}

CITC: Corrected item-total correlation; CRC: Category response curve; CTT: Classical test theory; HAND: Healthy Activity and Nutrition Directions; HH: Helping HAND; DIF: Differential item functioning; Infit: informationweighted fit statistic; IRM: Item response modeling; MNSQ: Mean square item fit index; MPIRM: Multidimensional polytomous item response modeling; NA: Niños Activos; Outfit: Outlier-sensitive fit statistic; PCM: Partial credit model; PP: Parenting practices; RSM: Rating scale model; TV: Television; TV PP: TV parenting practices; Wii: Wii Active Video Game; Yo: Years old.

\section{Competing interests}

The authors declare that they have no competing interests.

\section{Authors' contributions}

TC participated in the design of the study, conducted the psychometrics analyses and drafted the manuscript. TB, TO, SH, LF, JB, JM, and DT helped conceive the study, and participated in its design and helped to critically edit the manuscript. All authors read and approved the final manuscript.

\section{Acknowledgements}

This research was primarily funded by grants from NIH (R21 CA140670, R21 HD060925 and R21 CA66724-01). JAM was supported, in part, by a grant (K07CA131178) from the National Cancer Institute, National Institutes of Health. This work is also a publication of the USDA/ARS, Children's Nutrition Research Center, Department of Pediatrics, Baylor College of Medicine, Houston, Texas, and funded in part with federal funds from the USDA/ARS under Cooperative Agreement No. 58-6250-0-008. The contents of this publication do not necessarily reflect the views or policies of the USDA, nor does mention of organizations imply endorsement from the U.S.

government 
Received: 3 October 2012 Accepted: 22 March 2013

Published: 2 April 2013

\section{References}

1. Rideout VJ, Foehr UG, Roberts DF: Generation M2: Media in the lives of 8- to 18-year-olds. Henry J. Kaiser Family Foundation. 2010. http://www.kff.org/ entmedia/upload/8010.pdf

2. Robinson TN: Reducing children's television viewing to prevent obesity: a randomized controlled trial. JAMA 1999, 282:1561-1567.

3. Jackson DM, Djafarian K, Stewart J, Speakman JR: Increased television viewing is associated with elevated body fatness but not with lower total energy expenditure in children. Am J Clin Nutr 2009, 89:1031-1036.

4. Miller SA, Taveras EM, Rifas-Shiman SL, Gillman MW: Association between television viewing and poor diet quality in young children. Int J Pediatr Obes 2008, 3:168-176.

5. Paavonen EJ, Roine M, Pennonen M, Lahikainen AR: Do parental coviewing and discussions mitigate TV-induced fears in young children? Child Care Health Dev 2009, 35:773-780.

6. Schmidt ME, Haines J, O'Brien A, McDonald J, Price S, Sherry B, Taveras EM: Systematic review of effective strategies for reducing screen time among young children. Obesity (Silver Spring) 2012, 20:1338-1354.

7. Davison KK, Li K, Baskin ML, Cox T, Affuso O: Measuring parental support for children's physical activity in white and African American parents: The Activity Support Scale for Multiple Groups (ACTS-MG). Prev Med 2011, 52:39-43.

8. Jago R, Davison KK, Brockman R, Page AS, Thompson JL, Fox KR: Parenting styles, parenting practices, and physical activity in 10- to 11-year olds. Prev Med 2011, 52:44-47.

9. Valkenburg PM, Krcmar M, Peeters AL, Marseille NM: Developing a scale to assess three styles of television mediation: "Instructive mediation", "restrictive mediation", and "social coviewing". J Broadcast Electron Media 1999, 43:52-66.

10. Hambleton RK, Swaminathan H: Item Response Theory: Principles and Applications. Boston: Kluwer Nijoff Publishing; 1985.

11. Hambleton RK, Swaminathan H, Rogers HJ: Fundamentals of Item Response Theory. Newbury Park, CA: Sage Publications, Inc.; 1991.

12. Dennison BA, Erb TA, Jenkins PL: Television viewing and television in bedroom associated with overweight risk among low-income preschool children. Pediatrics 2002, 109:1028-1035.

13. Anderson DR, Huston AC, Schmitt KL, Linebarger DL, Wright JC: Early Childhood Television Viewing and Adolescent Behavior. Boston, MA: Basil Blackwell; 2001.

14. Certain LK, Kahn RS: Prevalence, correlates, and trajectory of television viewing among infants and toddlers. Pediatrics 2002, 109:634-642.

15. Bolt $D$, Stout W: Differential item functioning: Its multidimensional model and resulting SIBTEST detection procedure. Behaviormetrika 1996, 23:67-95.

16. Baranowski T, Abdelsamad D, Baranowski J, O'Connor TM, Thompson D, Barnett A, Cerin E, Chen TA: Impact of an active video game on healthy children's physical activity. Pediatrics 2012, 129:e636-e642.

17. O'Connor TM, Hilmers A, Watson K, Baranowski T, Giardino AP: Feasibility of an obesity intervention for paediatric primary care targeting parenting and children: Helping HAND. Child Care Health Dev 2011 [Epub ahead of print]

18. Springer DM: An examination of parental awareness and mediation of media consumed by fifth grade students [Doctoral Dissertation]. Manhattan, KS: Kansas State University; 2011.

19. Warren R: Parental mediation of preschool children's television viewing. J Broadcast Electron Media 2003, 47:394-417.

20. Nunnally JC: Psychometric Theory. 2nd edition. New York: McGraw-Hill; 1978.

21. SAS Institute Inc: SAS Version (9.2). Cary, NC: [Computer Software]; 2008

22. IBM Corp: IBM SPSS Statistics for Windows, version 20.0. Armonk, NY: IBM Corp; 2011 [Computer Software].

23. Reeve BB, Mâsse LC: Item response theory modeling for questionnaire evaluation. In Methods for Testing and Evaluating Survey Questionnaires. Edited by Presser S, Rothgeb JM, Couper MP, Lessler JT, Martin E, Martin J, Singer E. Hoboken, NJ: John Wiley \& Sons; 2004:247-273.

24. Costa PT, McCrae RR: The Revised NEO Personality Inventory (NEO PI-R) and NEO Five-Factor Inventory (NEO-FFI). Odessa, FL: Psychological Assessment Resources; 1992

25. Chernyshenko O, Stark S, Chan KY, Drasgow F, Williams B: Fitting item response theory models to two personality inventories: Issues and insights. Multivariate Behav Res 2001, 36:523-562.
26. Wright BD, Masters GN: Rating Scale Analysis. Chicago: MESA Press; 1982.

27. Andrich D: Application of a psychometric rating model to ordered categories which are scored with successive integers. Appl Psychol Meas 1978, 2:581-594

28. Andrich D: A rating formulation for ordered response categories. Psychometrika 1978, 43:561-573.

29. Bond TG, Fox CM: Applying the Rasch Model. 2nd edition. Mahwah, NJ: Lawrence Erlbaum Associates; 2001.

30. Smith RM, Schumacker RE, Bush MJ: Using item mean squares to evaluate fit to the Rasch model. J Outcome Meas 1998, 2:66-78.

31. Osteen P: An introduction to using multidimensional item response theory to assess latent factor structures. J Soc Social Work Res 2010, 1:66-82

32. Linacre JM: Investigating rating scale category utility. J Outcome Meas 1999, 3:103-122

33. Baranowski T, Allen DD, Masse LC, Wilson M: Does participation in an intervention affect responses on self-report questionnaires? Health Educ Res 2006, 21:198-109.

34. Watson K, Baranowski T, Thompson D: Item response modeling: an evaluation of the children's fruit and vegetable self-efficacy questionnaire. Health Educ Res 2006, 21:i47-57.

35. Paek I: Investigation of differential item function: comparisons among approaches, and extension to multidimensional context [Doctoral Dissertation]. Berkeley, CA: University of California; 2002.

36. Wilson M: Constructing Measures: An Item Response Modeling Approach. Mahwah, NJ: Lawrence Erlbaum Associates; 2005

37. Wu ML, Adams RJ, Wilson M, Haldane S: Conquest. Berkeley, CA: ACER; 2003 [Computer Software]

38. Angoff WH: Perspectives on differential item functioning methodology. In Differential Item Functioning. Edited by Holland PW, Wainer H. Hillsdale, NJ: Lawrence Erlbaum and Associates; 1993:3-24.

39. Shepard LA: Definition of bias. In Handbook of Methods for Detecting Test Bias. Edited by Berk RA. Baltimore, MD: Johns Hopkins University Press; 1982:9-30.

40. Embretson SE, Reise SP: Item Response Theory for Psychologists. Mahwah, NJ: Lawrence Erlbaum Associates, Inc.; 2000

41. Reeve BB, Fayers P: Applying item response theory modeling for evaluating questionnaire items and scale properties. In Assessing Quality of Life in Clinical Trials: Methods and Practices. 2nd edition. Edited by Fayers P. Hays R. New York: Oxford University Press; 2005:55-73.

42. Mantel N: Chi-square tests with one degree of freedom: Extensions of the Mantel-Haenszel procedure. J Am Stat Assoc 1963, 58:690-700.

43. Shealy R, Stout W: A model-based standardization approach that separates true bias/DIF from group ability differences and detects test bias/DTF as well as item bias/DIF. Psychometrika 1993, 58:159-194.

44. Shealy RT, Stout WF: An item response theory model for test bias. In Differential Item Functioning. Edited by Holland PW, Wainer H. Hillsdale, NJ: Lawrence Erlbaum Associates; 1993:197-240.

doi:10.1186/1479-5868-10-41

Cite this article as: Chen et al:: TV parenting practices: is the same scale appropriate for parents of children of different ages?. International Journal of Behavioral Nutrition and Physical Activity 2013 10:41.

\section{Submit your next manuscript to BioMed Central and take full advantage of:}

- Convenient online submission

- Thorough peer review

- No space constraints or color figure charges

- Immediate publication on acceptance

- Inclusion in PubMed, CAS, Scopus and Google Scholar

- Research which is freely available for redistribution 